\title{
Minding the gap between communication skills simulation and authentic experience
}

\section{Authors:}

Sarah Yardley*, Alison Irvine and Janet Lefroy

*corresponding author

Dr Sarah Yardley BM PGCertClinEd, MA, PhD, MRCP, NIHR Academic Clinical Lecturer in Medical Education and SpR in Palliative Medicine, Keele University Medical School, Keele, Staffordshire, ST55BG, T:01782 734694 F: 01782734637 syardley@doctors.org.uk

Dr Alison Irvine BAOxon BMBCh DCH DRCOG FRCGP MSc(MedEd), Teaching Fellow, School of Medicine, Clinical Education Centre, University Hospital of North Staffordshire NHS Trust, Newcastle Road, Stoke on Trent, ST4 6QG, T : 01782679682 alisonirvine@aol.com

Dr Janet Lefroy MBBS DCH DRCOG FRCGP MMedEd, Senior Lecturer in Medical Education, School of Medicine, Clinical Education Centre, University Hospital of North Staffordshire NHS Trust, Newcastle Road, Stoke on Trent, ST4 6QG, T: 01782679625 jlefroy@doctors.org.uk

Author contributions

SY conceived the idea for this paper based on her observations of difference, contrast and comparison in data generated as part of her doctoral thesis on authentic early experience. Her work led to the theory development using the concept of a 'gap' that might be used to potentiate educational value. SY wrote the first draft of the paper, contributed to the analysis and integration of data from all three studies for this purpose and finalised the submitted version.

AWI developed minding the gap strategies from themes within the background reading for her master's dissertation. She analysed data, supplied references, contributed to drafting and redrafting, including proof-reading the final version of the manuscript.

$\mathrm{JL}$ contributed to research data, analysis and formulation of the conclusions, and to drafting and amending the manuscript including the final version.

Document statistics: Abstract 300 words, Main Text 6553 words including 1102 of data quotations, 1 table, 1 figure, 58 references 


\begin{abstract}
Introduction: Exposure to concurrent simulated and authentic experiences during undergraduate medical education is increasing. The impact of gaps or differences between contemporaneous experiences has not been adequately considered. We address two questions: 'How do new undergraduate medical students understand contemporaneous interactions with simulated and authentic patients?'; 'How and why do student perceptions of differences between simulated and authentic patient interactions shape their learning?'

Methods: We conducted an interpretative thematic secondary analysis of research data comprising individual interviews $(n=23)$, focus groups ( 3 groups, $n=16)$, and discussion groups ( 4 groups, $n=26$ ) from two year cohorts of first year medical students. These methods generated data from 48 different participants of whom 17 provided longitudinal data. In addition data from routinely collected written evaluations of three whole first year cohorts (response rates $\geq 88 \%, n=378$ ) was incorporated into our secondary analysis data set. The primary studies and our secondary analysis were conducted in a single UK medical school with an integrated curriculum.
\end{abstract}

Results: Our analysis identifies that students generate knowledge and meaning from their simulated and authentic experiences relative to each other, resultant learning was different in quality due to meaning created from comparing and contrasting contemporaneous experiences. Three themes were identified that clarify how and why contrasting differences is an important process for learning outcomes. These are: preparedness, responsibility for safety, and perceptions of a gap between theory and practice.

Discussion: We propose a conceptual framework generated by re-framing common gap metaphors to develop educational strategies that might maximise useful learning from perceived differences. Educators need to 'mind' gaps in collaboration with students if synergistic learning is to be constructed from contemporaneous exposure to simulated and authentic patient interactions. The strategies need to be tested in practice by teachers and learners for utility. Further research is also needed to understand gaps in other contexts. 


\section{Main Text}

\section{INTRODUCTION}

Contemporaneous experience of simulated and authentic patient-student interactions occurs in medical curricula across the world and is required by the General Medical Council (1) in the UK. We define 'simulated patients' (SPs) as lay people trained to act as patients in medical interviews and give feedback from a patient perspective. Commonly these people are participating in role plays based in teaching environments remote from clinical practice. 'Authentic early experience' denotes human contact in clinical or social workplaces for the purpose of learning (2).

\section{Developing communication skills through simulated and authentic patient interactions}

Advantages of simulated interactions include reduced risk of harm (including psychological distress) to patients or students, the ability to control 'patient' supply and demand, partial control of the content of interactions and the possibility of 'practising' different scenarios and responses to develop appropriate knowledge, skills and behaviours (3-6), with accompanying patient-referenced feedback. In contrast authentic early experiences are a form of workplace-based learning, intended to encourage students to contextualise the curriculum and ease the transition into clinical learning during later years (7-10). Differences are seen by students when good practice ideals promoted in the classroom are not replicated by the healthcare professionals they see consulting in the workplace $(11,12)$ and when authentic patients respond differently to SPs. As with other forms of workplace-based (also called 'experience-based') learning, students require support to maximise the learning potential of these variable yet authentic experiences $(11,13,14)$.

The importance of physical and psychological fidelity during simulation is debated in the literature $(4,15)$, largely in relation to simulator equipment; less attention has been paid to that within SP encounters. A helpful addition to this debate is to take the social character of simulation into account by acknowledging that participants and organisers enter into a 'fiction contract', treating the simulation as if it were real in order to practice transferable skills (16). How critical physical or psychological fidelity are to supporting the fiction contract depends on whether the desired educational goals are to learn psychomotor dexterity, procedural knowledge, decision-making, interpersonal skills or team working norms and values or a combination of these activities. Simulation of communication skills is often conceptualised as preparation for workplace, 'bridging the gap' between the classroom and clinical practice $(17,18)$. This is based on the premise that authentic experience sequential to simulated experience is safer for both students and patients $(4$, 17-20) and that simulation offers an opportunity to instil understanding of ideal practice (21) prior to experience of pragmatism in authentic workplaces (22).

Few studies directly compare the two educational settings (23), consequently how new medical students handle contemporaneous experiences of simulated and real patient interactions has not been adequately considered (24). Students exposed sequentially to simulated patients in early years and then real patients in later years report that real patients were more focused on students understanding medical content than their ability to communicate (25). Students can be suspicious that simulated patients had been told to withhold information by faculty, whilst still describing simulated interactions as useful preparation for real encounters or practising worst case scenarios (25).

There is also evidence that learners commonly struggle to transfer knowledge between contexts (2628). Transfer will be impaired if there is a perceived gap between what is taught in medical school and the reality of medicine as practised in the workplace (29). This creates potential for dissonance between student experiences of simulation and authentic practice $(4,30)$. Unless there is understanding of how and why students conceptualise their experiences, and particularly how they 
handle these differences, we cannot seek to improve patient care through integrated simulationbased and authentic workplace-based education $(4,31,32)$.

\section{METHODS}

This is an exploratory study to clarify student perceptions of contemporaneous interactions with simulated and authentic patients so that we can better understand the consequences for development of communication skills. In this paper we present an interpretative thematic secondary analysis of data before developing a conceptual framework for educational strategies to make sense of, and learn from, gaps or differences.

\section{Methodological framework}

Qualitative secondary analysis is attracting increasing interest in social science research disciplines (see for example: 33-35) and amongst research funders. Although there is no universally agreed definition of secondary analysis it is a term used to describe situations where researchers conduct further analysis of one or more data sets for purposes not defined or predicted in the original study design (see Heaton (36) and Thorne (37), for an overview of different types of secondary analysis).The attractions of secondary analysis as a methodology include (A) facilitating data analysis across data sets (for example, when each individual data set provides relevant and complementary data to explore a particular question) and (B) the further exploration of unrelated novel questions or unexpected findings generated as a by-product of studies with a different focus. It has also been suggested that secondary analysis of data from different sources may improve generalisability of qualitative findings (38). Many of the potential criticisms of secondary analysis (aside from issues which apply to any qualitative approach whether primary or secondary), such as loss of contextual information, are negated or resolvable when researchers from the original studies are involved in a rigorous process of secondary analysis. We have re-examined data originally generated from first and second year students during research studies conducted by each of the authors (see table 1). All three of the original studies, while addressing different research questions, were situated within an interpretative constructionist paradigm, and so shared commonalities in theoretical perspective.

\section{INSERT TABLE 1 APPROXIMATELY HERE}

\section{Objectives}

The studies from which our data set originates were all designed to look at aspects of student interactions with either simulated or authentic patients (see table 1). During the primary analysis of one data set (11) an unexpected finding was observed by the first author of this paper: not only did students compare learning in different settings but this comparison led students to make value judgements about what was valid knowledge. Students were generating knowledge and meaning from their simulated and authentic experiences relative to each other. While one might reason that expanded learning could emerge from students' comparisons of simulated and authentic experiences, with each offering complementary aspects of learning, it is also possible that learning from either sort of experience might be reduced as students contrasted experiences when making value judgements. The impact of comparison and contrast on learning from concurrent simulated and authentic experiences has not previously been studied in detail. The other two authors of this paper had also separately identified a similar need to better understand the impact of students comparing and contrasting simulation with clinical experience from their own masters' studies (39, 40) and observations during teaching (41). Secondary analyses of qualitative data look at the data through a different 'lens' and/or with fresh research question(s). Our objective, therefore, was to explore and clarify effects of contemporaneous provision of both types of experience through two research questions: 'How do new undergraduate medical students understand contemporaneous interactions with simulated and authentic patients?' (in the study context 'new' refers to the first 
two years of medical school) and 'How and why do student perceptions of differences between simulated and authentic patient interactions shape their learning?'. The second of these questions emphasises our objective of developing understanding of learning outcomes, or consequences arising from exposure to difference.

\section{Setting}

All three of the studies from which we drew our data set were conducted in a single UK medical school with an integrated curriculum for undergraduates. The curriculum uses a hybrid model incorporating problem-based learning, experiential learning within the medical school, laboratory sessions, lectures and authentic early experience placements.

Students interact with simulated and authentic patients from the start of their studies. Authentic patients are encountered predominantly in clinical placements, though patients are also used in classroom teaching. In their first term, students have four classroom-based tutor-facilitated communication skills teaching sessions. The first explains and explores the use of role play in teaching and the principles of feedback. The following three sessions use simulated patients. The first clinical placement occurs between the $3^{\text {rd }}$ and $4^{\text {th }}$ session, and is supported by a student briefing at the end of the $3^{\text {rd }}$ session, and debriefing at the start of the $4^{\text {th }}$ session which prepare students for, and enable them to reflect upon, their first authentic patient experiences.

During simulated interactions in the early years there was no simulation of the environment, only of the 'patient' role. The general stated purpose of classroom sessions with simulated patients was to offer students practice prior to their interactions with authentic patients; each session has its own specific written learning objectives. During authentic early experience placements students were supervised (but not directly observed) by nominated professionals within workplaces. Usually, (among other activities), the supervisor would set up an encounter with a patient who the students would then interview in pairs.

All three original studies were subject to independent peer review and prospective ethical approval was gained from Keele University School of Medicine Research Ethics Committee for the elements of work in each study that exceeded normal procedures for evaluation of the curriculum (for which ethical approval is not currently required in this setting). All participants gave informed consent for the data contained in this paper to be used in research. The methodological framework of our secondary analysis was also peer reviewed.

\section{Data set}

We conducted our secondary analysis on data generated from research methods and routine evaluations. The complete data set comprised research data from individual interviews ( $n=23)$, focus groups ( 3 groups, total participants $n=16$ ), and discussion groups ( 4 groups, total $n=26$ ) taken from two sequential year cohorts (2007/2008 and 2008/2009 year entry) of undergraduate medical students. The interviews had been audio-recorded with first and second year undergraduate students participating in a study of meaning-making and knowledge construction from authentic early experience. Students from these year cohorts later participated in audio-recorded discussion groups (by which time the students were in the second and third years of their degree) which were transcribed verbatim. The focus groups were also audio-recorded and transcribed verbatim in a study of student experiences with simulated patients. Overall these methods generated data from 48 different participants of whom 17 provided longitudinal data due to sequential participation (a feature of one of the original studies (11) meant 14 students participated in sequential interviews and discussion groups, in addition three students who participated in this study also participated in one of the others (39)). We have ensured that no individual students' views are over-represented in our secondary analysis data set by cross-checking transcriptions. In addition routine written 
evaluation data obtained from three Year 1 cohorts of students ( $n=378$, as described in table 1 ) was incorporated into the secondary analysis data set. Given response rates for all forms of evaluation data were $\geq 88 \%$ we would expect that students who participated in other forms of data generation were represented in the routine evaluation data also, but due to anonymised access to the evaluation data cannot confirm this. Details of the conduct of each original study from which the data sets were drawn are outlined in table 1 where we have summarised the theoretical framework, original research questions, setting, recruitment, sampling and participation, and methods. We have sequentially recorded verbatim quotations (rather than retaining the different original data set classification systems) for this paper to assist readability. Selected quotations have been drawn from different individual participants.

\section{Analysis}

The data from all three sources were combined before conducting an interpretative thematic analysis addressing the research questions outlined in this paper. All text was read and coded for type of experience, subject matter, comparison or contrast narratives, and comments on similarities and differences between simulated and authentic patients. Similarities and differences between each data set were sought. Themes in the data were identified through discussion of these codes by all three authors. Data extracts are presented in the results section to illustrate specific points within the analysis. Attention was paid to the social construction of the data and the language used. Our interpretation was developed through a rethinking of existing 'gap' metaphors. This re-framing produced an alternative conceptual model for using difference and contrast to potentiate learning and enabled the development of our proposed educational strategies (see discussion).

\section{RESULTS}

Both forms of learning were well received amongst the student body as evidenced by levels of satisfaction reported in contemporary written routine evaluations. In this section we present three key cross-cutting themes derived from secondary analysis of data where students compare or contrast communication differences between simulated and authentic patient interactions, these are:

1. Preparedness: for being a student on placement or for becoming a doctor

2. Responsibility for safety: patient and student

3. Student perceptions of a gap between theory and practice

The initial analysis is presented below and our interpretation further developed in the next section.

\section{Preparedness: for being a student on placement or for becoming a doctor}

118 (99\%) of first year students on evaluating their introductory communication skills course in November 2007 and 121 (98\%) in November 2008 agreed that communication skills classes prepared them well for placements (39). In the interviews and discussion groups conducted a few months later by Yardley (11), however, although students reported their expectations of simulation to have been met, they also argued that it would not have been possible to fully prepare them for their experiences with authentic patients:

'although we were adequately prepared for placements, I didn't feel that prepared because I hadn't actually gone out and spoken to patients yet because ... what I mean is the actual development of getting better at talking to patients is by talking to more patients and, so I think I really needed to 
develop the confidence, really... get out in the real world before I felt adequately prepared for placements.'(S1) (11)

Students participating in focus groups (39) also reported satisfaction with the realism of the simulated patients but questioned whether learning arising from these sessions could really be directly considered as 'preparedness':

'I thought it [simulated sessions with student choice of level of patient emotion] was really useful, but a couple of weeks after that I had a placement where a patient did actually start crying. Even though it was useful and I knew more what to expect, you still feel completely overwhelmed when you are sat there in a room with two of you. Maybe because it was a male patient I felt that there was a guy sat there crying and you're there like what do we do, what have we done?....... because you know with the simulated patient that you can't offend them if you upset them, it's not actually...it doesn't prepare you that much for real emotion, you are still completely overwhelmed by it.' (S2)(39)

Both the students above imply that simulation is useful in acquiring skills but it is less useful for preparing the learner for how they are going to feel when faced with reality. For such students, the fiction contract (16) during simulation does not extend to consideration of their own feelings. Instead, students in simulation focus on personal performance, or the reactions of their peers and tutors.

Students particularly value the educational role of the simulated patient:

'... what is more helpful with the simulated patients is the feedback that they give you afterwards, because they've obviously done it plenty of times before - they know what they're looking for, they know what... they know what a good history is all about, so they can give constructive feedback which is invaluable really - simulated patients are really invaluable in that respect.' (S3)(11)

However, students in discussion groups framed interactions with simulated patients as more awkward or antagonistic than with authentic patients, as they were felt to require prescribed student behaviours to 'unlock' phases of the patient script, as illustrated here:

'Yes the simulated patients like, it's like they've been primed, they've only been told that they can say certain things if you ask a question in the correct way. If you don't say it in the correct way, they don't give you that bit of information that you need to then ask your next question whereas a normal patient you can just ask them one question and they can go on forever and you can pick up loads of points to then ask them.' (S4) (11)

The finding that students felt they were participating in a script during simulated sessions is not unique to this setting as illustrated in debates surrounding the hidden curriculum in multiple spheres of learning and fidelity issues within simulation. It does, however, suggest that students might need more support to engage in the 'fiction contract' discussed above (16). Nonetheless the 'artificial' aspects of simulated interactions did provide students with learning opportunities that would otherwise perhaps not have occurred. For example, the option of 'pausing' and seeking advice midinteraction promoted student learning:

'I think the pause and the rewind... commands were really useful, because you could stop and talk to the group and things like that and that helped a lot rather than carrying on to fail and then talking about how badly you failed. It gave you a chance to correct what you are doing if you were making a mistake.' (S5) (39) 
The use of 'gospel' as a metaphor by the following student could suggest a perception that the medical school, unlike the student, believes there is a single correct way to communicate. This is supported by the use of 'right' and 'wrong' when describing feedback:

'if they just gave us communication skills and left it at that, it would just be learning a set of theories or a set of questions... you can't take this rigid structure as gospel anyway, it's meant to be a framework which you work from because not every patient's gonna be the same... But it's... invaluable to have the grounding first... with... simulated patients... with a tutor there to guide you where you're going wrong and to tell you when you're going right... then actually going out and doing it.' (S6)(11)

Tutors, simulated patients and students are, in fact, instructed to facilitate feedback in terms of what worked and alternatives rather than right and wrong - although we do not know if this was always followed during the study sessions. Taken to a logical conclusion, these findings suggest that students could be feeling pressure to behave in one way in classrooms and another in workplaces. In their comments many students conceived the purpose of simulation sessions as limited to the short term goal of coping with authentic experiences as students. In contrast at least some of the students viewed authentic experiences as preparation for future practice. For these students the impact was considerable:

'Placements - all three were very different, memorable experiences that encouraged me through giving me a vision of what I could be doing in five years' time. They helped me understand the patient experience and communicate with patients' (S7) (41)

With respect to learning content and practically applicable knowledge for the future, the unpredictable agendas of authentic patients were reported as valuable opportunities to learn and derive meaning. Students could identify potential learning beyond the faculty designed objectives when interacting with authentic patients, for example understanding the patients' life:

'They might come out with... a lot of things which you don't expect or which you never asked but somehow it came out... they came out with something totally unrelated but still a good insight to their lives.' (S8) (11)

\section{Responsibility for safety: patient and student}

Placements can be a disappointment especially if providers seem unprepared or unwelcoming, and expected educational opportunities did not materialise. Some students in the 2010-2011 cohort reported 'the provider didn't even know we were coming!' (S9) (41), despite there being clear administrative processes to book and confirm placements well in advance of student visits. Some providers seemed unclear about students' intended educational objectives:

'When I went to placements, I felt I was abandoned sometimes and I didn't know what to do apart from interviewing patients. Someone should be beside me while I was interviewing the patient and I should be given feedback at the end. Therefore, I could learn from mistakes and I could improve my communication and interviewing skills' (S10) (41)

This comment also suggested simulation might be creating student dependence upon a level of supervision which is not always available in clinical practice. The student body had taken to heart concerns of some faculty about risk and potential harm arising from authentic interactions. The faculty intention as expressed in briefings was to reassure students that they should not be pressured into acting above their competencies. For some students, at least, it resulted in anxieties that limited them: 
'He (a workplace supervisor) just said out of the blue, 'would you like to take a history off the patient?' and I just thought right, well, I'd rather not do it terribly and, you know, potentially make the patient worse off because of it - why put her through a history that's not going to be properly taken...' (S6) (11)

'I'd say with reference to the communication skills, being able to get the practice in with simulated patients before was definitely beneficial rather than just getting straight out and interviewing a patient because the potential for mistakes is quite high'. (S11) (39)

Some students believed that authentic patients might not detect underperformance (expecting competency), which created a sense of responsibility in contrast to the 'safe' experience with simulated patients which created a sense of performance. The following example shows how a student's self-confidence is affected by the performance she perceives the patient expects:

'you know you can do it and you know that the patient's not going to know if you've done it wrong... when it's a normal patient... well they expect me to know what I'm doing, so... it's easier to have the confidence because there isn't somebody there to scrutinise you' (S12)(11)

Other students were more cautious, voicing concerns about upsetting patients and crossing the expected norms of lay interactions, which might produce unpredictable reactions from patients:

'You can't harm simulated patients... you can't really make them upset... whereas a real patient... they perceive us as doctors.' (S13) (11)

'there's a lot more to think about when you're with a real patient...you really are delving into their personal, private lives... whereas the simulated patients are told to react in a certain way, these patients could act any which way they want to... and you have to...go...a bit more cautious' (S14)(11)

For some students these unknowns are exciting and challenging, for others unsettling. A combination of simulation and authenticity was sometimes created by inviting authentic patients into classroom settings. These sessions were valued by the students and appeared to be viewed as less risky:

'They were really useful. The fact that they were very willing to talk about their experiences and were willing if you asked them anything. Their answer would be fantastic. You didn't feel worried to ask them a question because of the environment we were in, it just felt very open and easy to talk to them' (S15) (39)

\section{Student perceptions of a gap between theory and practice}

Some comments reveal a substantial gap from student perspectives:

'skills acquired in EL [experiential learning] are impossible to be applied on placement. EL and placement are completely different situations (S16) (41)

'they don't do it the way you teach us to' (S17) (41)

'whereas a real patient obviously isn't [primed by the medical school]... - so it just feels more like a real conversation... whereas I think with an SP obviously you're doing things to try and tick off the right things... what you learn would be quite different. On simulated patients you are basically practising what you have been taught during that session... - what you should do with consent and so on... It's quite rigid.' (S18)(11)

The clearest example of a student perceived gap between theory and practice related to the discussion of consent and/or confidentiality in the two types of interaction (41). In particular, the 
perception that the medical school was mistaken about the importance of consent and confidentiality was common amongst students. This was because although these aspects had been identified as important in the classroom, students had not seen placement providers explicitly talk about these issues at the start of every patient encounter in practice (41). Some concluded that simulated patients were following the medical school's rules rather than representing a valid patient perspective:

'I think simulated patients try to do things a lot more by the book, whereas real patients... they aren't as, you know, sort of straightforward as you might think - you wouldn't normally go through, confidentiality with them and then consent and that sort of stuff, 'cause they just... they don't see it as being important, whereas simulated patients will - that's only probably because they've been told to... by the medical school.'(S19) (11)

Despite the differing requirements for consent within clinical and primarily educational encounters (the latter predominantly applies to early patient interviews involving novice learners), none of the student interviewees described considering such nuances. Very few students appeared to realise that often practitioners had continuing professional understandings with their patients, or that some patients might, in certain circumstances, see consent or confidentiality as of vital importance. A student may spontaneously draw the conclusion that real patients do not see confidentiality and consent as important, rather than considering alternative explanations such as, for example, that real patients believe observing good practice in these areas to be a given and, therefore, not requiring discussion.

\section{INTERPRETATIVE ANALYSIS AND DISCUSSION}

To interpret the meaning of the three themes described above we have developed a conceptual framework suggesting alternative meanings for gap metaphors that teachers, supervising clinicians and learners might find useful in developing educational strategies for making sense of, and learning from, gaps or differences. The three themes identified from our secondary analysis can be conceptualised as contributing to an overarching theory-practice gap between simulated and authentic patient interactions. Our key finding is not that simulated patients are perceived differently to authentic patients (we suggest that this will be self-evident) but a clarification of how students actively use their perceptions of difference to compare and contrast and so construct learning from their contemporaneous experiences. Our analysis identifies that students generate knowledge and meaning from their simulated and authentic experiences relative to each other, with similarities or differences seen in the workplace reinforcing or negating classroom learning in complex ways. When difference was identified during interactions with patients, students made meaning about what was 'real' in the workplace and what was important to the medical school faculty (identified through simulated patients and tutors who were perceived as agents of the medical school). Students found it difficult to suspend the sense of giving a performance in the classroom. Authenticity produced a contrasting sense of responsibility towards patients while many students remained reluctant to be assertive about their learning needs. In authentic situations students believed patients might not detect underperformance, as the patients would be expecting competency. This meant that some students were actually more at ease during real patient experiences, but the responsibility caused others some discomfort.

We have interpreted student talk of the exemplar differences and resultant meaning-making illustrated in data above as 'gaps' needing recognition and explanation if we are to maximise learning opportunities from contemporaneous exposure to simulated and authentic early experiences. 'Gap(s)' are common metaphors in both everyday language and the fields of medicine and medical education. For example, the gap between theory and practice, between expectations and achievement, or between teaching delivered and learning generated. They are present in communication skills literature $(17,18)$ and in clinical and teaching practice. The use of the physical 
concept of 'gaps' is often associated with solutions to remove the gap, or eliminate its effects, illustrated through the common use of phrases such as 'bridging the gap' or 'closing the gap' in everyday life. These terms suggest that gaps are conceptualised as sources of disconnection or risk rather than metaphorical spaces for development. This is in contrast to the work of Vygotsky who conceptualised learning and meaning as social and cultural rather than individual processes (44). He describes a metaphorical gap or space (the zone of proximal development) to define the additional potential a learner has to expand understanding, through interaction with other agents and structures, beyond what might be achieved alone. To understand and explain gaps requires a critical approach to the purpose of metaphor, and consideration of whether different meanings could underlie the metaphor. Our interpretation re-frames the meaning of gap metaphors to develop educational strategies for teachers and learners.

\section{Educational opportunities in the theory-practice gap}

Both simulated and authentic patient-student interactions are social practices: contextual events which occur in space and time where people interact with each other, artefacts and the environment for learning purposes (16). We have already drawn on the work of Dieckmann et al. by building on their use of the term 'fiction contract' to describe how participants who 'suspend disbelief' and conduct simulated interactions 'as-if' authentic may benefit more in terms of educational value (16). In addition, we suggest that the educational value of both simulated and authentic interactions may be synergistically increased through explicit attention to, and discussion of, difference. To date, few studies have directly compared the two educational settings. Our findings demonstrate that students continually make comparisons for themselves, and that the spontaneous meanings which students construct of difference can lead to 'competitive contrast' where the student rejects learning constructed from simulation that appears to conflict with the practice they observe in authentic workplaces. Exposure to both modes of teaching could be better used to expand overall learning by actively encouraging students to critically appraise their simulated and authentic experiences in comparison to each other, asking why difference occurs and seeking to assimilate and accommodate the resulting understanding into their evolving conceptual frameworks of good clinical practice.

\section{Moving from 'competitive contrast' to 'constructive comparison' of difference}

Theoretical and empirical evidence in other areas of medicine has previously shown that reasoning and meaning-making often involves the use of comparison and contrast $(4,23-25,45,46)$. Left to spontaneous devices for meaning-making, difference is more striking than similarity $(47,48)$. Figure 1 summarises our evolving conceptual framework of the two teaching environments and the physical, intellectual and emotional gaps between them. We are proposing that these gaps, or at least the 'solutions' to them, need to be reconceptualised to maximise the educational value of students concurrently engaging in simulated and authentic patient interactions. Metaphors can be helpful in conceptualisation but can also lead to assumptions of common understanding rather than discussion of what different people perceive the work of the metaphor to be. Rather than seeking to 'close' or even to 'bridge' the gaps we suggest, based on our findings, that educators - within medical schools and workplaces alike - in collaboration with their students, need to 'mind' (that is, think differently and critically about) gaps.

In order to move students' learning from 'competitive contrast' of ideals with the pragmatic and nuanced realities of workplace learning (as this reasoning has been shown to result in rejection of the ideals in our data above), we need to develop educational strategies which allow students to make 'constructive comparisons', and generate learning from differences. This finding is not dissimilar to that of van der Zwet et al. (49) in general practice clerkships who describe how developmental space is needed to learn and develop a professional identity. Space is created when context and interactions with others allow students opportunities to 'mind their learning' with educators' support (49). 
We suggest that educators need to be mindful of gaps between student experience of simulated and authentic patient interactions. The educator has a role to play in driving a continual cycling of constructive comparison (indicated by the arrows in Figure 1 and the panel describing the educator's role). We suggest the following strategies for putting mindedness into practice:

1. Don't ignore a gap as this risks paradoxical meaning-making, rejection of ideals in face of contrast in reality, creation of dichotomies and misunderstandings. For example, Roger Kneebone, who writes extensively and thoughtfully about the use of simulation in surgery, used the ha-ha wall as a metaphor for understanding the different perspectives of novices and experts to illustrate the dangers of ignoring a gap (50).

2. Manage the gap: educators who recognise and understand gaps can work collaboratively with students to discuss perceived differences and make constructive comparisons. This requires explicit expectation of difference, making the educator's role one of facilitating student meaning-making including encouraging students to theorise about how and why identified differences occur. It also requires acknowledging that placements may require a level of adaptability and self-directedness over and above that which students may have needed in the classroom and providing the necessary support for students during the process and debriefing elements of their interactions, not relying solely on preparedness.

3. Use it - being 'mindful' of the gap: use of Epstein's term is intentional (51). Mindfulness can be considered an element of students' reflective practice leading to personal and professional development (52). Tutors also need to be mindful, however, of how they portray the other side of the gap, and of their potent effect as role-models (positive and negative). Regardless of the quality, breadth and depth of 'communication skill toolkits' offered to students in classrooms, simulation cannot achieve the same potency as their exposure to the daily professional practice of qualified clinicians.

\section{Strengths and limitations}

Qualitative research studies usually produce data which exceeds the researchers' original purpose and which generates interesting findings beyond the specific research questions for which the study was designed. A marker of robust and rigorous qualitative analysis is to seek to interpret the data rather than simply to seek confirmation of expected findings. It is, therefore important that if unexpected findings are identified that these are given due consideration. Secondary analysis provides a mechanism for this. The differences noted by students impact on their learning from either setting and we found that they actively construct meanings to explain differences. Our research questions focused not on whether students perceive difference, but rather on how students perceive differences and what effect this has on their learning. The congruence and replication of findings within our data can be considered as a form of triangulation through the process of secondary analysis. However, there are also potential limitations to our work. A secondary analysis (or meta-analysis or systematic review for that matter) will depend, at least in part, on the quality of the original studies, although as we returned to the original data our analysis was not dependent on any pre-existing interpretation. Data from all three original studies was derived from the same UK Medical School. It is possible that elements of the findings represent the circumstances of that particular school. Yardley (11) and Lefroy (39) sampled the same cohort in $2007 / 2008$ (the first cohort of a new curriculum in the medical school) so this cohort's views might not be representative of other years once the curriculum was embedded. We also do not know what the impact was of two of the authors (Irvine \& Lefroy) teaching on the classroom communication skills programme at the time of the research. We are, however, reassured by the congruence of their findings with those of Yardley (11), who was then only known to the students as an education researcher. It is possible to construct sequential participation of some students within the data as either a strength or weakness. Some of the original studies deliberately generated data longitudinally. Within the secondary analysis it could be argued, for example, that this overlap is a 
strength, as the consistency of views across studies suggests students were not simply trying to please particular researchers or meet particular study expectations. As with any secondary analysis we cannot know if our participants might have offered different perspectives or different explanations of their handling of perceived gaps had such questions been directly put to them in a primary qualitative study. This is an area requiring further exploration alongside the further work we suggest below.

\section{Conclusions and further work}

'Minding the gap' is an interpretative metaphor that we offer on the basis of our analysis. We do so to suggest that students will construct meaning in perceived gaps between classroom and authentic practice due to an intrinsic human desire to reconcile or explain lived experiences. Metaphor is defined as understanding one conceptual domain (the target domain) in terms of another conceptual domain (the source domain), which leads to the identification of a conceptual metaphor (42). The metaphor itself may not be spoken out loud but apparent (in our data, for example, the phrase 'they don't do it the way you teach us' (S17) clearly illustrates the presence of a conceptual gap even if not explicitly named as such) or interpreted in interactions between people, for example, teachers and learners. It is important to pay attention to not just what is said or not said, but how and why, in order to more fully understand the meaning for the speaker.

This research shows that learning context is significant, but also that different contexts can be positively contrasted by students to potentiate learner-created meaning. We have generated a conceptual framework that challenges people to think critically about the use of gap metaphors and what they personally mean when invoking gaps as a metaphorical tool. We hope our suggested educational strategies will be of practical use for teachers and supervisors engaging in simulated and authentic patient experiences with students by providing insight into students' perceptions and reasoning. In the medical school at which this work was conducted first year students are now explicitly briefed to think about the 'gap' between simulated and authentic patient interactions and given guidance on how differences may be opportunities to extend their learning.

It is important to recognise that interactions both in simulated and authentic contexts can be subject to complex interpretations by students. We should neither reject simulation as lacking in reality nor be seduced into expecting it to solve all the challenges of developing effective communication skills in practice. Instead, we should seek to find ways of minding the gap to increase the learning potential of concurrent simulation and authentic experiences.

In order to clarify how gaps between theory and practice influence learning, and whether more specific discussion of differences is beneficial, further research is required. We hope that the concept of 'minding the gap' might be now considered more widely and in other contexts in order to explore whether this has potential to encourage the development of transferable learning. Further studies might also useful consider how student expectations of contemporaneous interactions with simulated and authentic patients are formed and whether interventions might target this process to further potentiate development of communication skills. The conceptual framework and educational strategies we suggest need to be tested in practice by teachers and learners for utility. Outcomes and impact of using our conceptual framework and educational strategies for teaching and learning should be evaluated through further research. In addition, research to understand theory-practice gaps in other contexts might also usefully contribute to understanding the importance of differences for students in shaping their learning. 


\section{References}

1. General Medical Council. Tomorrow's Doctors. London: General Medical Council; 2009.

2. Littlewood, S., Ypinazar, V., Margolis, S. A., Scherpbier, A.J.J.A., Spencer, J., Dornan, T. Early practical experience and the social responsiveness of clinical education: Systematic review. British Medical Journal. 2005;331:387-91.

3. Lefroy, J, Brosnan, C, Creavin, S. Some like it hot: Medical student views on choosing the emotional level of a simulation. Medical Education. 2011 Apr;45:354-61.

4. Kneebone, R. L., Scott, W., Darzi, A., Horrocks, M. Simulation and clinical practice: Strengthening the relationship. Medical Education. 2004;38:1095-102.

5. Bradley, P., Postlethwaite, K. Simulation in clinical learning. Medical Education. 2003;37 Suppl 1:15 .

6. McGaghie, W. C., Siddall, V.J., Mazmanian, P.E., Myers, J., American College of Chest Physicians Health and Science Policy Committee. Lessons for continuing medical education from simulation research in undergraduate and graduate medical education: Effectiveness of continuing medical education: American College of Chest Physicians evidence-based educational guidelines. Chest. 2009 Mar;135(3 Suppl):62S-8S.

7. Dornan, T., Littlewood, S. Margolis, S. A., Scherpbier, A.J.J.A., Spencer, J., Ypinazar, V. How can experience in clinical and community settings contribute to early medical education? A BEME systematic review. Medical Teacher. 2006;28:3-18.

8. Hopayian, K., Howe, A., Dagley, V. A survey of UK medical schools' arrangements for early patient contact. Medical Teacher. 2007;29:806-13.

9. Yardley, S., Littlewood, S., Margolis, S. A., Scherpbier, A.J.J.A., Spencer, J., Ypinazar, V., Dornan, T. What has changed in the evidence for early experience? Update of a BEME systematic review. Medical Teacher. 2010;32:740-6.

10. Dornan, T., Bundy, C. What can experience add to early medical education? Consensus Survey. British Medical Journal. 2004;329:834-9.

11 Yardley, S. Understanding authentic early experience in undergraduate medical education [dissertation]. Keele: Keele University 2011.

12. Yardley, S., Brosnan, C., Richardson, J. The consequences of authentic early experience for medical students: Creation of student mētis. Medical Education. In press.

13. Dornan, T., Boshuizen, H., King, N., Scherpbier, A.J.J.A. Experience-based learning: A model linking the processes and outcomes of medical students' workplace learning. Medical Education. 2007; 41:84-91.

14. Yardley, S., Brosnan,C., Richardson, J., Hays, R. Authentic Early Experience in Medical Education: a socio-cultural analysis identifying important variables in learning interactions within workplaces. Advances in Health Science Education. 2012. Dec 5. doi: 10.1007/s10459-012-9428-2 
15. Demaria, S.,Jr, Bryson, E. O., Mooney, T.J., Silverstein, J.H., Reich, D. L., Bodian, C., Levine,A.I. Adding emotional stressors to training in simulated cardiopulmonary arrest enhances participant performance. Medical Education. 2010 Oct;44:1006-15.

16. Dieckmann, P., Gaba, D., Rall, M. Deepening the theoretical foundations of patient simulation as social practice. Simulation in Healthcare. 2007;2:183-93.

17. Bligh, J. Bleakley, A. Distributing menus to hungry learners: Can learning by simulation become simulation of learning? Medical Teacher. 2006;28:606-13.

18. Malhotra, A., Gregory, I., Darvill, E., Goble, E., Pryce-Roberts, A., Lundberg, K., Konradsen S, Hafstad, H. Mind the gap: Learners' perspectives on what they learn in communication compared to how they and others behave in the real world. Patient Education and Counselling. 2009;76:385-90.

19. du Boulay, C. Medway, C. The clinical skills resource: A review of current practice. Medical Education. 1999;33:185-91.

20. Gaba, D. M. The future vision of simulation in health care. Quality \& Safety in Health Care. 2004;13 Suppl 1:i2-10.

21. Hanna, M., Fins, J.J. Power and communication: Why simulation training ought to be complemented by experiential and humanist learning. Academic Medicine. 2006;81(3):265-70.

22. Smith, B. From simulation to reality - breaking down the barriers. The Clinical Teacher. 2006;3:112-7.

23. Bokken, L., Rethans, J.J, Jöbsis, Q., Duvivier, R., Scherpbier, A.J.J.A., van der Vleuten, C.P.M. Instructiveness of real patients and simulated patients in undergraduate medical education: $A$ randomised experiment. Academic Medicine. 2010;85:148-54.

24. Bokken, L., Rethans, J.J., Scherpbier, A.J.J.A., van der Vleuten, C.P.M. Strengths and weaknesses of simulated and real patients in the teaching of skills to medical students: A review. Simulation in Healthcare. 2008;3:161-9.

25. Bokken, L., Rethans, J.J., van Heurn, L., Duvivier, R., Scherpbier, A.J.J.A., van der Vleuten, C. P.M. Students' views on the use of real patients and simulated patients in undergraduate medical education. Academic Medicine. 2009;84:958-63.

26. Norman, G. Teaching basic science to optimize transfer. Medical Teacher. 2009;31:807-11.

27. Dornan, T., Hadfield, J., Brown, M., Boshuizen, H., Scherpbier, A.J.J.A. How can medical students learn in a self-directed way in the clinical environment? Design-based research. Medical Education. 2005;39:356-64.

28. Brown, J. Transferring clinical communication skills from the classroom to the clinical environment: Perceptions of a group of medical students in the United Kingdom. Academic Medicine. 2010 Jun;85:1052-9.

29. Eva, K. W. What every teacher needs to know about clinical reasoning. Medical Education. 2004;39:98-106. 
30. Okuda, Y., Bryson, E. O, DeMaria, Jr. S., Jacobson, L., Quinones, J., Shen, B. Levine, A.I. The utility of simulation in medical education: What is the evidence? Mount Sinai Journal of Medicine.

2009;76(4):330-43.

31. Ellaway, R. H., Kneebone, R., LaChapelle, K. \& Topps, D. Practica continua: Connecting and combining simulation modalities for integrated teaching, learning and assessment. Medical Teacher. 2009;31:725-31.

32. Kneebone, R. L., Kidd, J., Nestel, D., Barnet, A., Lo, B., King, R. et al. Blurring the boundaries: Scenario-based simulation in a clinical setting. Medical Education. 2005;39:580-7.

33. Bishop, L. Ethical sharing and reuse of qualitative data. Australian Journal of Social

Issues. 2009;44:255-272.

34. Broom, A., Cheshire, L., \& Emmison, M. Qualitative researchers' understandings of their practice and the implications for data archiving and sharing. Sociology. 2009;43:1163-1180.

35. Valles, M., Miguel, S., Corti, L., Tamboukou, M., Baer, A. Qualitative archives and biographical research methods. an introduction to the FQS special issue. Forum: Qualitative Social Research, [Online] 2011: 12 Available from: http://www.qualitativeresearch.net/index.php/fqs/article/view/1755.

36. Heaton, J. Reworking qualitative data. 2004. SAGE, London.

37. Thorne, S. Ethical and Representational Issues in Qualitative Secondary Analysis.

Qualitative Health Research, 1998;8;547-555.

38. Hammersley, M. Qualitative data archiving: Some reflections on its prospects and problems. Sociology, 1997;31:131-142.

39. Lefroy, J. How can the existing communication skills curriculum be optimised, in the light of experience here and elsewhere, and in congruence with the rest of the curriculum? [dissertation]. Keele: Keele University; 2010.

40. Irvine, A. W. Evaluation of the use of peer physical examination (PPE) in the teaching of basic physical examination skills to medical undergraduates [dissertation]. Stafford: Staffordshire University; 2011.

41. Irvine, A.W. Lefroy, J. E. Addressing the classroom-clinical practice divide. In: Communication in undergraduate medical education conference; 24th March; University of Manchester. Manchester: UK Council of Communication Teaching in Undergraduate Medical Education; 2011.

42. Rees, C., Knight, L.V. Wilkinson, C.E., 2007. ' Doctors being up there and we being down here': a metaphorical analysis of talk about student/doctor-patient relationships. Social Science and Medicine. 2007:65;725-737.

43. Marinker, M. Myth, paradox, and the hidden curriculum. Medical Education, 1997;31;293-298. 
44. Kozulin, A., Chaklin, S., Karpov, Y., et al. 2003. Vygotsky's educational theory in cultural context. Cambridge: Cambridge University Press.

45. Cook, S. Mind the theory/practice gap in nursing. Journal of Advanced Nursing. 1991;16:1462-9.

46. Norman, G. Research in clinical reasoning: Past history and current trends. Medical Education. 2005;39:418-27.

47. Piaget, J. The psychology of intelligence. London: Routledge; 1950.

48. Helmore, G. Piaget, J. : A practical consideration. Oxford: Pergamon Press; 1969.

49. van der Zwet, J., Zwietering, P. J, Teunissen, P. W., van der Vleuten, C.P.M., Scherpbier, A.J.J.A. Workplace learning from a socio-cultural perspective: Creating developmental space during the general practice clerkship. Advances in Health Sciences Education. 2011;16:359-73.

50. Kneebone, R. Perspective: Simulation and transformational change: The paradox of expertise. Academic Medicine. 2009 Jul;84(7):954-7.

51. Epstein, R. M. Mindful practice. JAMA. 1999 Sep 1;282(9):833-9.

52. Shapiro, J., Kasman, D., Shafer, A. Words and wards: A model of reflective writing and its uses in medical education. J. Medical Humanities. 2006;27(4):231-44.

53. Riessman, C. K. Narrative methods for the human sciences. Thousand Oaks, CA: Sage; 2008.

54. Alderson, P., Farsides, B., Williams, C. Examining ethics in practice: Health service professionals' evaluations of in-hospital ethics seminars. Nursing Ethics. 2002;9:508-21.

55. Frey, J. H., Fontana, A. The group interview in social research. Social Science Journal. 1991;28:175-87.

56. Williams, C., Ehrich, K., Farsindes, B., Scott, R. Facilitating choice, framing choice: Staff views on widening the scope of preimplantation genetic diagnosis in the UK. Social Science and Medicine. 2007;65:1094-105.

57. Morgan, D. L. Focus groups as qualitative research. 2nd ed. Newbury Park, California: Sage; 1997.

58. Yardley, S., Brosnan, C., Richardson, J. Sharing methodology: a worked example of theoretical integration with qualitative data to clarify practical understanding of learning and generate new theoretical development. Medical Teacher 2012; Oct 26. doi: 10.3109/0142159X.2012.733045 


\begin{tabular}{|c|c|c|c|}
\hline Study & Yardley (2011) & Lefroy (2010) & Irvine \& Lefroy (2011) \\
\hline $\begin{array}{l}\text { Theoretical } \\
\text { framework }\end{array}$ & $\begin{array}{l}\text { Orientated towards the principles of constructionism, } \\
\text { interactionism and interpretivism. Socio-cultural theories were } \\
\text { used to interrogate empirical data and empirical data was used } \\
\text { to refine and develop these theories within the field of Medical } \\
\text { Education. }\end{array}$ & $\begin{array}{l}\text { Action research to design and evaluate the curriculum } \\
\text { during its first year of delivery drawing on adult learning } \\
\text { theories within a constructivist approach to learning. }\end{array}$ & Interpretative analysis of evaluation data (free text) \\
\hline $\begin{array}{l}\text { Original research } \\
\text { questions }\end{array}$ & $\begin{array}{l}\text { 'How and why do students construct useful knowledge and } \\
\text { meaning-making from authentic early experience?' and 'How } \\
\text { and why do students make authentic early experiences work } \\
\text { for them?' }\end{array}$ & $\begin{array}{l}\text { In the communication skills curriculum what curricular } \\
\text { content should be taught, by what methods, in what } \\
\text { locations, by whom, to achieve which desired learning } \\
\text { outcomes with respect to the first year of the curriculum? }\end{array}$ & $\begin{array}{l}\text { The survey asked for six open text responses:- } \\
\text { Comments on learning activities } \\
\text { Unit } 1 \text { : Emergencies : What did you enjoy the most? } \\
\text { What aspects of this unit have you found most challenging? } \\
\text { Unit } 2: \text { Infections and Immunity: What did you enjoy the } \\
\text { most? } \\
\text { List the two best things about Semester } 1 . \\
\text { List the two things that could be improved about Semester } 1 \\
\text { and suggestions for how they could be improved }\end{array}$ \\
\hline Setting & $\begin{array}{l}\text { UK medical school established in } 2002 \text { and implementing a } \\
\text { new locally designed curriculum from 2007/8. Students } \\
\text { participated in simulated patient interactions (during } \\
\text { classroom communication skills training) and in real patient } \\
\text { interactions (during authentic early experience placements in } \\
\text { workplaces) from the start of their first year. Students were } \\
\text { provided with a paper briefing prior to each session in the } \\
\text { classroom or workplace outlining intended communication } \\
\text { skills learning outcomes. }\end{array}$ & $\begin{array}{l}\text { The same UK medical school as Yardley (2011) in the two } \\
\text { years surrounding the launch of its new curriculum. The } \\
\text { action research team included stakeholders such as } \\
\text { communication skills tutors, clinical tutors from workplace } \\
\text { settings, a } 4^{\text {th }} \text { year medical student representing the } \\
\text { student perspective and simulated patients to represent } \\
\text { informed lay perspectives. }\end{array}$ & $\begin{array}{l}\text { As described for Yardley (2011). } \\
\text { The cohort of Year } 1 \text { students are divided into } 15 \text { tutor-led } \\
\text { small groups for each communication skills teaching session. } \\
5 \text { groups run at a time and each session is followed by a tutor } \\
\text { debriefing involving the } 5 \text { tutors reporting back to the lead } \\
\text { tutor who compiles a written lead tutor report. }\end{array}$ \\
\hline $\begin{array}{l}\text { Recruitment, } \\
\text { sampling and } \\
\text { participation }\end{array}$ & $\begin{array}{l}\text { Students were recruited from academic years commencing in } \\
2007 / 8 \text { and } 2008 / 9 \text {. Participation was voluntary following } \\
\text { recruitment via email and lecture announcements. Students } \\
\text { were sampled from both year } 1 \text { and year } 2 \text { of the } \\
\text { undergraduate degree as the authentic early experience } \\
\text { programme spanned both years. } \\
2007 / 8 \text { cohort: } n=4 \text { (individual interviews alone), } n=8 \\
\text { (individual interviews and discussion group), } n=3 \text { (discussion } \\
\text { group alone) } \\
2008 / 9 \text { cohort } n=5 \text { (individual interviews alone), } n=6 \\
\text { (individual interviews and discussion group), } n=9 \text { (discussion } \\
\text { group alone). }\end{array}$ & $\begin{array}{l}\text { The study population comprised Year } 1 \text { students whose } \\
\text { undergraduate degree commenced in } 2007 / 8 \text { and } 2008 / 9 \text {, } \\
\text { plus the tutors and simulated patients working with these } \\
\text { student cohorts. A subset of students in the } 2007 / 8 \text { cohort } \\
\text { was also recruited to join focus group discussions (3 groups, } \\
\mathrm{n}=16 \text { in total). This subset volunteered following } \\
\text { announcements in a lecture and online. }\end{array}$ & $\begin{array}{l}\text { All } 133 \text { Year } 1 \text { students in the cohort commencing in } \\
2010 / 11 \text { were sent an electronic evaluation using } \\
\text { 'SurveyMonkey TM' software at the end of semester } 1.100 \% \\
\text { responded. In addition all students were invited to give } \\
\text { verbal feedback on their first placement experience to their } \\
\text { small group tutor in the fourth communication skills session, } \\
\text { at the end of Semester } 1 \text {. The feedback from } 15 \text { tutors, taken } \\
\text { over the } 3 \text { sets, after this session was summarised into } 3 \text { lead } \\
\text { tutor reports (students' views were hence subject to } \\
\text { reinterpretation). }\end{array}$ \\
\hline Methods & $\begin{array}{l}\text { Interviews and discussions groups (when results from prior } \\
\text { interviews were shared with students divided by year and } \\
\text { previous participation) were used to generate data between } \\
\text { January } 2009 \text { and March 2010. Students had been on between } \\
\text { two and four placements in their current year of study, and the } \\
\text { second year students had completed up to six placements in } \\
\text { their first year of study. Participants were asked to provide } \\
\text { examples of their experiences and encouraged to explain their }\end{array}$ & $\begin{array}{l}\text { Routine evaluation data } 2007 / 8 \text { cohort: } 121 / 137 \text { Year } 1 \\
\text { students ( } 88 \% \text { of cohort). } 57 \% \text { of responders were female, } \\
11.6 \% \text { graduates and } 9.9 \% \text { repeating the year. } \\
2008 / 9 \text { cohort: } 124 / 133 \text { Year } 1 \text { students }(93 \%), 60 \text { ( } 45 \% \text { of } \\
\text { respondents) were female, } 14.5 \% \text { graduates and } 5.6 \% \\
\text { repeating the year } \\
\text { Analysis of routine evaluation data for communication skills } \\
\text { programme collected through a student questionnaire }\end{array}$ & $\begin{array}{l}\text { Students' open text comments to the } 6 \text { survey questions } \\
\text { were transcribed verbatim. Thematic analysis identified } 72 \\
\text { comments from } 54 \text { students of relevance to simulated } \\
\text { patient teaching and authentic patient interactions. } \\
\text { Thematic analysis of the elements of the } 3 \text { lead tutor reports } \\
\text { relevant to comparison and contrast between simulated and } \\
\text { authentic patient encounters. }\end{array}$ \\
\hline
\end{tabular}




\begin{tabular}{|c|c|c|c|}
\hline & $\begin{array}{l}\text { own interpretations of these during semi-structured interviews } \\
\text { (53). Interviews included discussion of the expectations, } \\
\text { processes and consequences of authentic early experiences. } \\
\text { The discussion groups (54-56) were designed to allow student } \\
\text { participants to comment on developing findings and to } \\
\text { enhance understanding of the student perspective through } \\
\text { discussion of views amongst peers to identify areas of } \\
\text { consensus or difference, and collective meaning-making (57). } \\
\text { Data were audio-recorded and independently transcribed. } \\
\text { Three complementary overarching data types were generated; } \\
\text { phenomenological themes, narrative (content and } \\
\text { structure/language) and presented meaning. Analysis was } \\
\text { conducted in discussion with three other researchers using } \\
\text { mixed qualitative methods that drew on strategies from } \\
\text { thematic analysis, narrative and discourse analysis and } \\
\text { interpretative phenomenological analysis. Further details of } \\
\text { the original study including the full study design and } \\
\text { methodology are available in (58) }\end{array}$ & $\begin{array}{l}\text { containing } 16 \text { questions and space for free text. For further } \\
\text { details including the evaluation forms see Lefroy, Brosnan \& } \\
\text { Creavin (3). Students self-identified comparisons between } \\
\text { communication skill sessions and their authentic early } \\
\text { experiences during the process of evaluation. } \\
16 \text { students took part in three focus groups at the end of } \\
\text { the first cycle of Year } 1 \text { (2007/8 cohort) - seven male and } \\
\text { nine female of whom two were graduates. Allocation to } \\
\text { focus groups was by availability and in order to disperse } \\
\text { PBL group members as much as possible. Efforts were also } \\
\text { made to obtain an even gender balance within groups. } \\
\text { Student focus groups were analysed using a modified } \\
\text { grounded theory approach. Data was transcribed and } \\
\text { coded by the author into themes. The moderator and } \\
\text { assistant were known to the students as the course } \\
\text { evaluators and were not their tutors. The focus groups } \\
\text { explored a range of issues relating to the new curriculum, } \\
\text { and as part of this broader evaluation each group was } \\
\text { asked to discuss their experiences of communication skills } \\
\text { sessions and placements. } \\
\text { Focus groups were audio-recorded and transcribed with } \\
\text { written consent from participants. Thematic analysis of } \\
\text { transcript data was performed using NVivo } 2.0 \text { software. } \\
\text { Tentative interpretations were developed at the time of } \\
\text { data collection and the relevant literature was scanned to } \\
\text { widen the interpretation. Assumptions were discussed by } \\
\text { the action research group in light of findings, highlighting } \\
\text { exceptions and seeking explanations for apparent } \\
\text { disagreement. For further details see Lefroy ( } 39 \text { ). }\end{array}$ & \\
\hline $\begin{array}{l}\text { Original data re- } \\
\text { used in secondary } \\
\text { analysis }\end{array}$ & Interview and discussion group verbatim transcripts. & $\begin{array}{l}\text { Free text from questionnaires. Transcripts from focus } \\
\text { groups. }\end{array}$ & $\begin{array}{l}\text { Verbatim transcriptions from survey (tutor reports providec } \\
\text { contextual information). }\end{array}$ \\
\hline $\begin{array}{l}\text { Unique } \\
\text { participants } \\
\text { contributing } \\
\text { research data to } \\
\text { the secondary } \\
\text { analysis data set }\end{array}$ & $\begin{array}{l}35 \text { unique participants contributed through either an individual } \\
\text { interview or discussion groups }\end{array}$ & $\begin{array}{l}13 \text { unique (in addition to Yardley 2011) participants } \\
\text { contributed through focus groups }\end{array}$ & Not applicable \\
\hline $\begin{array}{l}\text { Routine evaluation } \\
\text { data included in } \\
\text { the secondary } \\
\text { analysis data set }\end{array}$ & Not applicable & $N=245$ & $\mathrm{~N}=133$ \\
\hline
\end{tabular}




\section{Figure 1 How educators can be 'gap-conscious' in the teaching of medical undergraduate}

\section{communication skills}

Simulated experience:
- Student centred
- Medical school teaching
environment
- Levelled to the learner
- Structured, planned,
supported, predictable,
often highly integrated
with curriculum
- Consistent delivery of
teaching experiences
- Trained educators with
protected time
- Simplified/standardised
cases
- Patient illness is generally
absent or simulated
- Supervised practice
- Safe place for mistakes
- Performance-related
feedback
objectives
pretend/rehearsal and
requires the 'fiction
contract'
- Seen as learning
-

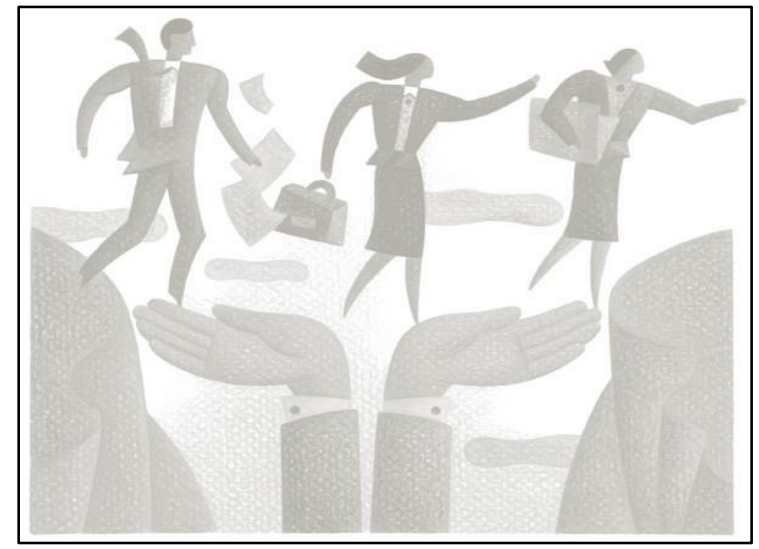

\section{The educators' role}

\section{Don't ignore the gap}

- Recognise that an educational conversation and a clinical encounter are different - be explicit about the value of a 'fiction contract'

- Prepare students intellectually and emotionally for an important transition

- $\quad$ Simulation per se is not the bridge, but make it as realistic as possible with contextualised scenarios, credible patients and clinically-oriented teachers

- Don't widen the gap by promoting unachievable idealism in classroom and assessment rather than what is attainable in clinical practice

\section{Manage the gap}

- Careful planning of placements and good crossboundary communication

- $\quad$ Briefings for placement, students and tutors to define expectations

- Contextual orientation in placements

- Debriefings in placement and classroom

- Enable students to capitalise on the unplanned and unpredictable through educator-supported critical analysis

\section{Be mindful of the gap}

- Use differences as a substrate for learning

- Use reflection, peer discussion \& tutor-facilitation to make sense of differences

- Bring complexity \& uncertainty into the classroom

- Be wary of the potential dangers of simulation

- Be conscious of the impact of positive and negative role models and encourage debate of what is 'good' communication in different situations
Authentic experience:

- Patient centred

- Workplace clinical environment

- Patients' conditions unpredictable, so not necessarily integrated with curriculum

- Different learning experiences

- Teachers may not be formally trained in medical education

- Complexity - of illness, team interactions, patients' needs

- Unwell, anxious patients

- Service commitments can compete with teaching

- Harm avoiding and risk averse culture

- Student performance may be unobserved without feedback

- Driven by patients' clinical needs

- Seen as 'real'

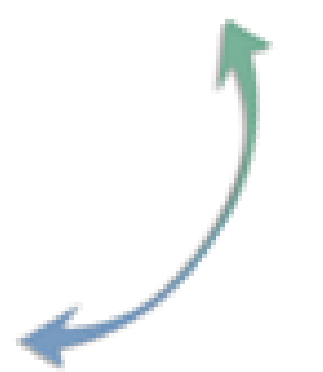

